Sharif University of Technology
Scientia Iranica
Transactions E: Industrial Engineering
http://scientiairanica.sharif.edu

\title{
Maintenance policy selection considering resilience engineering by a new interval-valued fuzzy decision model under uncertain conditions
}

\author{
N. Foroozesh ${ }^{a}$, S.M. Mousavi ${ }^{b}$, M. Mojtahedi ${ }^{c, *}$, and H. Gitinavard ${ }^{a}$ \\ a. Department of Industrial Engineering and Management Systems, Amirkabir University of Technology, Tehran, Iran. \\ b. Department of Industrial Engineering, Faculty of Engineering, Shahed University, Tehran, Iran. \\ c. Faculty of Built Environment, University of New South Wales, Sydney, Australia.
}

Received 13 February 2019; received in revised form 13 February 2020; accepted 8 June 2020

\author{
KEYWORDS \\ Maintenance policy; \\ Resilience engineering; \\ Interval-valued fuzzy \\ sets; \\ Possibilistic statistical \\ concepts; \\ Monte Carlo \\ simulation; \\ Distinguishing index.
}

\begin{abstract}
Different maintenance policies including Preventive Maintenance (PvM) and Predictive Maintenance (PdM) have been introduced to enhance the operation of systems. Maintenance professional experts have faced numerous challenges in distinguishing between proper maintenance policies among which causes of failure, accessibility, and capability of maintenance should be regarded seriously. Moreover, most organizations do not have a deliberate and compelling model for evaluating maintenance policies under uncertainty to deal with real-world conditions. The aim of this paper is to introduce a new Interval-Valued Fuzzy (IVF) decision model to select a maintenance policy based on order inclination with comparability to ideal solutions through Monte Carlo simulation. This paper introduces novel separation measures and a new IVF-distinguished index based on Possibilistic Statistical Concepts (PSCs) so that maintenance Decision-Makers (DMs) feel aided in ranking maintenance policy candidates. Also, Resilience Engineering (RE) factors are considered based on conventional evaluation criteria. Finally, the steps of the proposed IVF model-based PSCs are applied to survey a real case in the manufacturing industry. Results of the presented model are compared with those existing in the recent literature and the outcome could help maintenance personnel in identifying the best policy systematically.
\end{abstract}

(C) 2022 Sharif University of Technology. All rights reserved.

\section{Introduction}

Appropriate maintenance not only extends the framework's lifetime, which will keep the life-cycle cost down, but also significantly contributes to the general performance of an organization in the manufacturing

*. Corresponding author. Tel.: +61 (2) 93855970 E-mail addresses: sm.mousavi@shahed.ac.ir (S.M. Mousavi); m.mojtahedi@unsw.edu.au (M. Mojtahedi)

doi: $10.24200 /$ sci. 2020.52928 .2952 industry $[1,2]$. Moreover, proper maintenance contributes to the reduction of the total cost of production systems $[3,4]$.

Different maintenance policies have been presented, e.g., Preventive Maintenance (PvM) and Predictive Maintenance ( $\mathrm{PdM}$ ), to enhance the reliability of a plant or a system [5]. Maintenance policy is assumed to be critical in giving direction for maintenance planning and management in how to deal with plants or systems. Optimal maintenance policy should be adopted to promote the reliability and reduce the failure risk of a plant to ensure greater 
investment. Note that every maintenance policy may enjoy some strengths and suffer weaknesses. Subsequently, selection and evaluation of a proper policy is a standout amongst the critical issues for maintenance Decision-Makers (DMs) or managers. The significance of selecting and evaluating an appropriate maintenance policy is distinctive in different manufacturing plants or systems. Evaluating and selecting a suitable maintenance policy in continuous plants or systems can be more straightforward than compound systems due to the failure of devices or equipment, thus generating a manufacturing line.

Panagiotidou and Tagaras [6] stated that an appropriate maintenance policy would lessen the likelihood of equipment failure and enhance the working condition of the equipment in a plant or system. According to Al-Najjar and Alsyouf [7], maintenance policy influences the total costs related to operating expenses; yet, the results of a wasteful maintenance policy lead directly to high maintenance costs. Numerous studies have investigated several maintenance approaches while a few have addressed the selection and evaluation of an appropriate arrangement in production systems.

The selection and evaluation of the maintenance policy does not rely on a single factor or criterion $[8,9]$. Consequently, maintenance approach evaluation is considered as the issue of Multi-Criteria DecisionMaking (MCDM). A review of the related literature indicates that the essential factor or criterion is maintenance cost, as examined by numerous researchers; for instance, Pascual and Ortega [10] and BartholomewBiggs et al. [11] focused on this issue. In different studies, it was found that a few elements take fuzzy or qualitative values or forms. A few researchers including Yuniarto and Labib [12] and Marmier et al. [13] used fuzzy conditions in maintenance.

Because of the difficulty in selecting the best maintenance policy, various strategies have been proposed to overcome this deficiency [14-17]. Among the proposed strategies, the MCDM is the most popular framework that has been executed in considering the issue of selection and evaluation of maintenance candidates [18,19]. A well-known MCDM method, namely Analytical Hierarchy Process (AHP), was employed by Labib et al. [20]. Bevilacqua and Braglia [21] presented and solved the best and appropriate maintenance policy for a plant or system in the manufacturing industry. Dey [22] materialized AHP to decide on the best and suitable maintenance policies for oil pipelines. Other than utilizing AHP, the Technique for Order of Preference by Similarity to Ideal Solution (TOPSIS) was additionally considered and utilized by Shyjith et al. [23].

Chatterjee and Kar [24] first characterized the granulation of linguistic information in heterogeneous (fuzzy, rough, interval, or crisp) contexts for group decision-making problems. Second, they constructed a flexible MCDM framework integrating the AHP with the VIekriterijumsko KOmpromisno Rangiranje (VIKOR) method in the granular domain to assess weights of different criteria and prioritize alternatives. This methodology was applied to a plastic manufacturing organization. Another study presented a hybrid algorithm based on the intuitionistic fuzzy-VIKOR method to assess five potential supplier alternatives based on five criteria and from the perspectives of four DMs in a case study [25].

An article paper in the medicinal framework suggested an algorithmic methodology with emphasis on Intuitionistic Fuzzy Soft Set (IFSS). This methodology was guided by the group decision model through the use of cardinals of IFSS. Likewise, it utilized choice matrix as a significant parameter that depended on decision parameters of individual master [26]. Another study developed a fuzzy expert system to diagnose the hypertension risk for different patients based on a set of symptoms and rules. Next, a neuro-fuzzy system was designed for the same set of symptoms and rules using three different types of learning algorithms [27]. Das et al. [28] proposed a robust decision-making approach through intuitionistic trapezoidal fuzzy number and fuzzy linguistic quantifier to compute the decisionmaker's uncertain optimism degree. The applicability of the proposed approach to a site selection problem of nuclear power plant was demonstrated.

Moreover, productive endeavors directed at coordinating the MCDM strategy with other diverse systems have been made. Bertolini and Bevilacqua [29] as well as Arunraj and Maiti [30] executed the AHP by coordinating it with Goal Programming (GP) to evaluate and select suitable and appropriate maintenance alternatives. Utilizing the consolidated techniques allowed DMs to examine the issue of maintenance selection at the point of interest, considering the resource burden. Triantaphyllou et al. [31] and Luce [32] provided a selection method to choose the best effective maintenance strategy given the costs obtained by different maintenance alternatives. Murthy and Asgharizade [33] utilized game theory to direct a choice based on the client's needs to choose, having an administration contract for the maintenance of outsources.

Tahir et al. [34] utilized another maintenance optimization model to perform the calculations through a decision support system. Sachdeva et al. [35] proposed an approach that deals with the definition of a ranking of various modes of Failure Modes and Effects Analysis (FMEA) and AHP techniques. Kodali et al. [36] built up an analytic hierarchy constant sum method for supporting maintenance alternatives or systems. Meselhy et al. [37] illustrated that periodicity metrics 
could adequately improve their decision on selecting fitting maintenance policies.

A combination of fuzzy concepts and MCDM methods has been broadly presented for Maintenance Policy Evaluation Problem (MPEP) because of its adaptability in measuring the vagueness of the information. A combination of fuzzy logic and AHP was done in Wang and Elhag [5] and Labib [38]. A number of studies have discovered the business related to the combination of AHP and GP (e.g., [5,39]). Given that AHP is a mainstream strategy utilized as a part of taking care of MPEP, it confronts a few constraints including uneven scale judgments, instability, and imprecision in the pair-wise correlation process. Therefore, there are a few endeavors that can overcome these troubles. For instance, Pariazar et al. [40] proposed a reception of rough set theory into AHP to remove the possible irregularity existing in AHP as much as possible.

Chan and Prakash [41] employed fuzzy TOPSIS in deciding on the appropriate maintenance candidate from a monetary figure of legitimacy. Besides the mix of different methods and tools with AHP, other combined works done by Al-Najjar and Alsyouf [7], Jafari et al. [42], and Li et al. [43] exist. Pourjavad et al. [44] focused on evaluating maintenance strategy in the mining industry based on Analytical Network Process (ANP) and TOPSIS. Ding and Kamaruddin [45] developed a maintenance policy selection model with FMEA and TOPSIS. Ding et al. [46] conducted a literature review and provided directions on maintenance policy optimization over the last two decades. To choose an appropriate maintenance policy through identification of the risk of failures, Nazeri and Naderikia [47] presented a fuzzy hybrid approach consisting of FMEA, Decision-Making Trials and Evaluation Laboratory (DEMATEL) technique, and ANP. For a case study, the presented methodology was applied to the assessment and awareness of the risk of failure modes for a railroad organization.

Dealing with uncertainty in the evaluation of maintenance policies considering different assessment criteria and handling real-world conditions in manufacturing systems are the main concerns of this paper. To this end, new fuzzy modeling, called Interval-Valued Fuzzy (IVF), is proposed for complex maintenance decisions with comparability to the ideal solutions using Monte Carlo simulation. The extension of fuzzy logic is more suitable than conventional uncertainty modeling to represent the degree of certainty for each of maintenance policies in the interval form. This fuzziness may promote reliability and lessen the failure risk and low confidence in the manufacturing systems without increasing the investment. In addition, a novel possibilistic statistical decision approach based on compromise ratio modeling is presented for the selection of maintenance policy by comparability to
IVF ideal solutions. Also, a new ranking index is introduced based on two high values of Possibilistic Mean (PM) and low Possibilistic Standard Deviations (PSDs). It could help support maintenance DMs in recognizing the best maintenance policy systematically. For a comprehensive assessment approach to the maintenance policy selection, this paper takes into account Resilience Engineering (RE) factors besides conventional evaluation criteria to deal with the problem.

The absence of a strategy with high capacity in analyzing and ranking maintenance policy with the highest scope of information has been disappointing in many cases. Likewise, in certain examples, quantitative and subjective criteria might be utilized continuously; this requires a technique to represent information simultaneously. Otherwise, a maintenance policy exists on the mix of proportionate quantitative and subjective criteria. A significant number of appraisal criteria for providers are quantifiable and there is no requirement for quality evaluations by DMs.

In this paper, a new decision-making model under IVF uncertainty is presented via similarity to ideal solutions with Monte Carlo simulation along with PM and PSD matrices. In addition, novel separation measures and a new IVF-distinguished index are introduced based on Possibilistic Statistical Concepts (PSCs). Characterized criteria and ambiguously characterized quantitative and subjective criteria are incorporated in the proposed decision-making process. Finally, a literature review of decision-making methods and the main contributions of this paper for selecting a maintenance policy are reported in Table 1 .

The rest of this study is organized as follows. Section 2 gives an understanding of the IVF logic. Section 3 provides steps of implementing the introduced approach by clarifying alternatives and choice criteria with brief depictions. The illustrative case of MPEP in the manufacturing industry is given in Section 4. The outcomes are given and concluded in Section 5.

\section{Basic definitions}

Fundamental operations as well as concepts of IVFSs and possibility theory are briefly provided.

The arithmetic operations between $\tilde{A}$ and $\tilde{B}$ as two typical IVTF numbers:

$$
\tilde{A}=\left[\tilde{A}^{L}, \tilde{A}^{U}\right]=\left[\left(a_{1}^{L}, a_{2}^{L}, a_{3}^{L}\right),\left(a_{1}^{U}, a_{2}^{U}, a_{3}^{U}\right)\right],
$$

and:

$$
\tilde{B}=\left[\tilde{B}^{L}, \tilde{B}^{U}\right]=\left[\left(b_{1}^{L}, b_{2}^{L}, b_{3}^{L}\right),\left(b_{1}^{U}, b_{2}^{U}, b_{3}^{U}\right)\right],
$$

are reported as follows [55]:

Addition operation: 
Table 1. Review of decision-making methods on literature for selecting maintenance policy.

\begin{tabular}{|c|c|c|c|c|c|c|c|c|c|}
\hline \multirow[b]{2}{*}{ Ref. } & \multicolumn{9}{|c|}{ Characteristics of decision-making methods } \\
\hline & $\begin{array}{l}\text { Crisp } \\
\text { data }\end{array}$ & $\begin{array}{c}\text { Fuzzy } \\
\text { data }\end{array}$ & $\begin{array}{c}\text { IVF } \\
\text { numbers }\end{array}$ & $\begin{array}{c}\text { Fuzzy } \\
\text { possibilistic } \\
\text { statistical } \\
\text { approach }\end{array}$ & $\begin{array}{l}\text { Criteria } \\
\text { weights }\end{array}$ & $\begin{array}{c}\text { Linguistic } \\
\text { terms }\end{array}$ & $\begin{array}{c}\text { Simulation } \\
\text { analysis }\end{array}$ & $\begin{array}{c}\text { Hybrid } \\
\text { approach }\end{array}$ & $\begin{array}{c}\text { Resilience } \\
\text { engineering } \\
\text { factors }\end{array}$ \\
\hline$[21]$ & $\sqrt{ }$ & - & - & - & $\sqrt{ }$ & $\sqrt{ }$ & - & - & - \\
\hline$[7]$ & $\sqrt{ }$ & $\sqrt{ }$ & - & - & $\sqrt{ }$ & $\sqrt{ }$ & - & $\sqrt{ }$ & - \\
\hline$[48]$ & $\sqrt{ }$ & $\sqrt{ }$ & - & - & $\sqrt{ }$ & $\sqrt{ }$ & - & - & - \\
\hline$[5]$ & $\sqrt{ }$ & $\sqrt{ }$ & - & - & $\sqrt{ }$ & $\sqrt{ }$ & - & $\sqrt{ }$ & - \\
\hline$[34]$ & $\sqrt{ }$ & $\sqrt{ }$ & - & - & - & $\sqrt{ }$ & - & $\sqrt{ }$ & - \\
\hline$[35]$ & $\sqrt{ }$ & - & - & - & $\sqrt{ }$ & $\sqrt{ }$ & - & $\sqrt{ }$ & - \\
\hline$[36]$ & $\sqrt{ }$ & - & - & - & $\sqrt{ }$ & $\sqrt{ }$ & - & $\sqrt{ }$ & - \\
\hline$[39]$ & $\sqrt{ }$ & $\sqrt{ }$ & - & - & $\sqrt{ }$ & $\sqrt{ }$ & - & $\sqrt{ }$ & - \\
\hline$[30]$ & $\sqrt{ }$ & - & - & - & $\sqrt{ }$ & $\sqrt{ }$ & - & $\sqrt{ }$ & - \\
\hline$[49]$ & $\sqrt{ }$ & - & - & - & $\sqrt{ }$ & $\sqrt{ }$ & - & $\sqrt{ }$ & - \\
\hline [44] & $\sqrt{ }$ & - & - & - & - & - & - & $\sqrt{ }$ & - \\
\hline$[50]$ & $\sqrt{ }$ & - & - & - & - & $\sqrt{ }$ & - & $\sqrt{ }$ & - \\
\hline [41] & $\sqrt{ }$ & $\sqrt{ }$ & - & - & $\sqrt{ }$ & $\sqrt{ }$ & - & - & - \\
\hline$[51]$ & $\sqrt{ }$ & $\sqrt{ }$ & - & - & $\sqrt{ }$ & $\sqrt{ }$ & - & $\sqrt{ }$ & - \\
\hline$[46]$ & $\sqrt{ }$ & - & - & - & - & - & - & $\sqrt{ }$ & - \\
\hline$[52]$ & - & $\sqrt{ }$ & - & - & $\sqrt{ }$ & $\sqrt{ }$ & - & - & - \\
\hline$[47]$ & - & $\sqrt{ }$ & - & - & $\sqrt{ }$ & $\sqrt{ }$ & - & $\sqrt{ }$ & - \\
\hline [53] & - & $\sqrt{ }$ & - & - & $\sqrt{ }$ & $\sqrt{ }$ & - & $\sqrt{ }$ & - \\
\hline [54] & - & $\sqrt{ }$ & - & - & $\sqrt{ }$ & $\sqrt{ }$ & - & - & - \\
\hline $\begin{array}{l}\text { Proposed } \\
\text { research }\end{array}$ & $\checkmark$ & $\sqrt{ }$ & $\sqrt{ }$ & $\sqrt{ }$ & $\sqrt{ }$ & $\sqrt{ }$ & $\sqrt{ }$ & $\sqrt{ }$ & $\sqrt{ }$ \\
\hline
\end{tabular}

$$
\begin{aligned}
\tilde{A} \oplus \tilde{B}= & {\left[\left(a_{1}^{L}+b_{1}^{L}, a_{2}^{L}+b_{2}^{L}, a_{3}^{L}+b_{3}^{L}\right),\right.} \\
& \left.\left(a_{1}^{U}+b_{1}^{U}, a_{2}^{U}+b_{2}^{U}, a_{3}^{U}+b_{3}^{U}\right)\right] .
\end{aligned}
$$

Subtraction operation:

$$
\begin{aligned}
\tilde{A}-\tilde{B}= & {\left[\left(a_{1}^{L}-b_{3}^{L}, a_{2}^{L}-b_{2}^{L}, a_{3}^{L}-b_{1}^{L}\right),\right.} \\
& \left.\left(a_{1}^{U}-b_{3}^{U}, a_{2}^{U}-b_{2}^{U}, a_{3}^{U}-b_{1}^{U}\right)\right] .
\end{aligned}
$$

Multiplication operation:

$$
\begin{aligned}
\tilde{A} \otimes \tilde{B}= & {\left[\left(a_{1}^{L} \times b_{1}^{L}, a_{2}^{L} \times b_{2}^{L}, a_{3}^{L} \times b_{3}^{L}\right),\right.} \\
& \left.\left(a_{1}^{U} \otimes b_{1}^{U}, a_{2}^{U} \otimes b_{2}^{U}, a_{3}^{U} \otimes b_{3}^{U}\right)\right] .
\end{aligned}
$$

Division operation:

$$
\begin{aligned}
\tilde{A} \div \tilde{B}= & {\left[\left(a_{1}^{L} \div b_{3}^{L}, a_{2}^{L} \div b_{2}^{L}, a_{3}^{L} \div b_{1}^{L}\right),\right.} \\
& \left.\left(a_{1}^{U} \div b_{3}^{U}, a_{2}^{U} \div b_{2}^{U}, a_{3}^{U} \div b_{1}^{U}\right)\right] .
\end{aligned}
$$

Let $\tilde{A}$ and $\tilde{B}$ be two triangular IVF numbers; then, the distance between $\tilde{A}$ and $\tilde{B}$ is provided by Eq. (5) [56], as shown in Box I.

PM estimation and possibilistic variance of triangular fuzzy number $\tilde{A}$ are provided as follows [57-60]:

$$
\begin{aligned}
M(\tilde{A}) & =\int_{0}^{1} \gamma((a-(1-\gamma) \tau)+(a+(1-\gamma) \tau)) d \gamma \\
& =a+\frac{1}{6}(\sigma-\tau),
\end{aligned}
$$

$$
d(\tilde{A}, \tilde{B})=\sqrt{\frac{1}{6}\left[\left(a_{1}^{L}-b_{1}^{L}\right)^{2}+\left(a_{2}^{L}-b_{2}^{L}\right)^{2}+\left(a_{3}^{L}-b_{3}^{L}\right)^{2}+\left(a_{1}^{U}-b_{1}^{U}\right)^{2}+\left(a_{2}^{U}-b_{2}^{U}\right)^{2}+\left(a_{3}^{U}-b_{3}^{U}\right)^{2}\right]} .
$$




$$
\begin{aligned}
\operatorname{Var}(\tilde{A}) & =\int_{0}^{1} \gamma((a-(1-\gamma) \tau)+(a+(1-\gamma) \sigma))^{2} d \gamma \\
& =\frac{1}{24}(\sigma+\tau)^{2}
\end{aligned}
$$

\section{Introduced model}

In this paper, a new analysis of Monte Carlo simulation is integrated into the IVF decision to better evaluate the DM or expert preferences and opinions. In fact, unlike the previous deterministic models, the proposed modeling with the help of IVF sets can provide greater flexibility for selecting a proper maintenance policy regarding the uncertain/vague data given the lack of information. Also, possibilistic measures of mean and variance for fuzzy numbers are taken into account in the model to incorporate more complete information for possibility functions than conventional approaches. In this paper, notations of lower and upper PM values are introduced. The interval-valued PM, crisp PM value, and crisp possibilistic variance of a continuous possibility distribution are defined, which are consistent with the extension principle and well-known definitions of expectation and variance in probability theory. The theory developed in this paper is sufficiently motivated by the principles introduced in Dubois et al. [61] and by the possibilistic interpretation of the ordering introduced in Goetschel and Voxman [62].

The flowchart of the introduced model-based PM and PSD with Monte Carlo simulation is depicted in Figure 1. First, it is assumed that:

- $X=\left\{X_{i} \mid i=1, \ldots, m\right\}$ is a set of maintenance policies;

- $C=\left\{C_{j} \mid j=1, \ldots, n\right\}$ is a set of criteria for the MPEP.

Since the information on maintenance policy options is uncertain, DMs can take an IVF $\tilde{A}_{i j}$ to express judgment on maintenance policy option $x_{i}$ through policy attribute $C_{j}$.

The MCDM of MPEP with IVF and PSCs can be given by Eq. (8) as shown in Box II, where:

$$
\begin{aligned}
& {\left[\left(\left(a_{i j}\right)_{1}^{L}\left(a_{i j}\right)_{2}^{L},\left(a_{i j}\right)_{3}^{L}\right),\left(\left(a_{i j}\right)_{1}^{U}\left(a_{i j}\right)_{2}^{U},\left(a_{i j}\right)_{3}^{U}\right)\right]} \\
& \quad=\left[\left(a_{i j}^{L}-\tau_{i j}^{L}, a_{i j}^{L}, a_{i j}^{L}+\sigma_{i j}^{L}\right),\left(a_{i j}^{U}-\tau_{i j}^{U}, a_{i j}^{U}, a_{i j}^{U}+\sigma_{i j}^{U}\right)\right] .
\end{aligned}
$$

Steps of the introduced model for MPEP are given below:

Step 1. Identify criteria for the MPEP;

Step 2. Determine the importance of attributes $j$ for the MPEP. Weights of criteria, $w_{j}(j=1, \ldots, n)$,

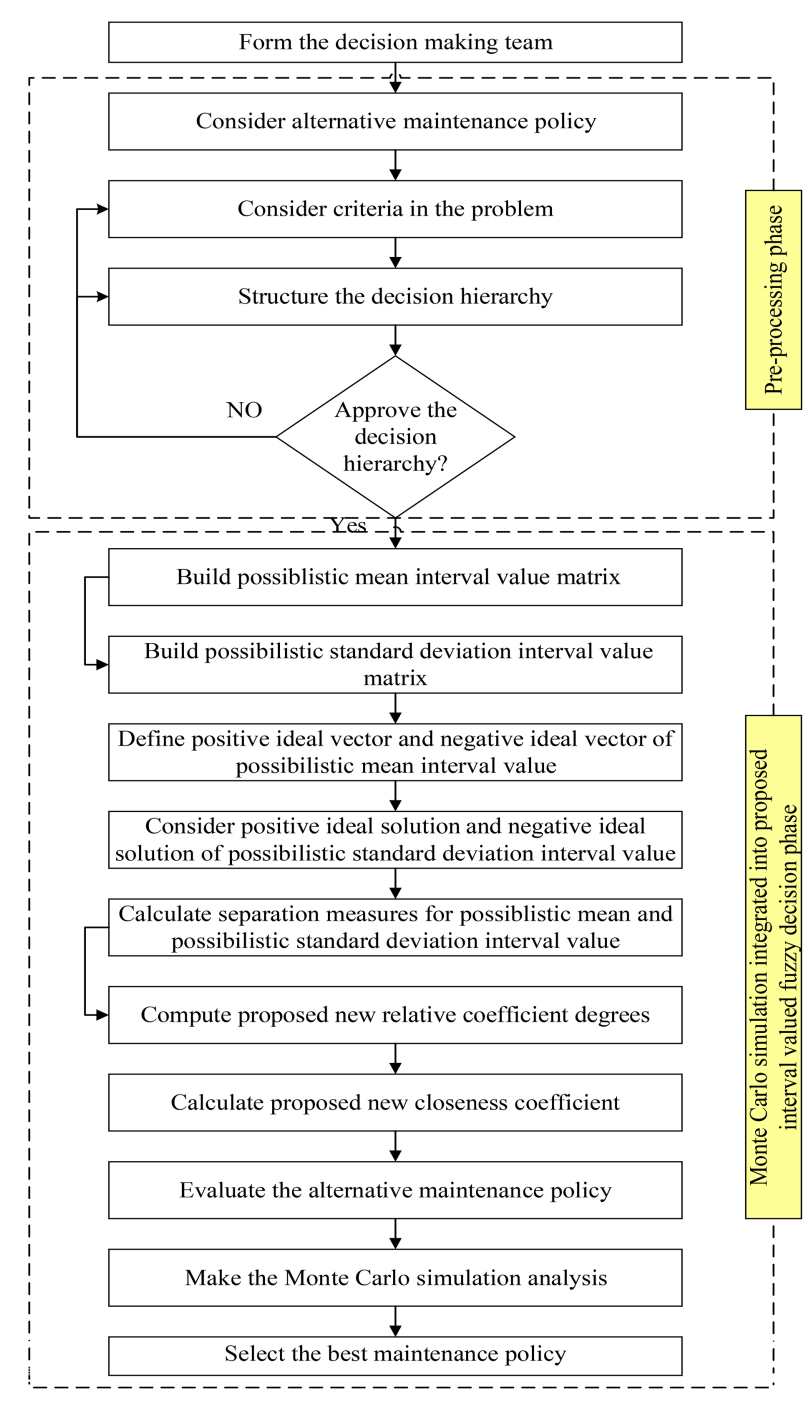

Figure 1. Flowchart of the proposed interval-valued fuzzy model with Monte Carlo simulation.

are in the range of $[0,1], 0 \leq w_{j} \leq 1, j=1, \ldots, n$, $\sum_{i=1}^{n} w_{j}=1$;

Step 3. Convert IVF matrix into a normalized matrix of maintenance policy candidates:

$$
\begin{aligned}
\left(\tilde{a}_{i j}^{\prime}\right) & =\left\lfloor\left(\left(a_{i j}^{\prime}\right)_{1}^{L},\left(a_{i j}^{\prime}\right)_{2}^{L},\left(a_{i j}^{\prime}\right)_{3}^{L}\right),\right. \\
& \left.\left(\left(a_{i j}^{\prime}\right)_{1}^{U},\left(a^{\prime}{ }_{i j}\right)_{2}^{U},\left(a_{i j}^{\prime}\right)_{3}^{U}\right)\right\rfloor \\
& =\left[\left(\frac{a_{i j}^{L}-\tau_{i j}^{L}}{\left(a_{i j}^{U}+\sigma_{i j}^{U}\right)^{+}}, \frac{a_{i j}^{L}}{\left(a_{i j}^{U}+\sigma_{i j}^{U}\right)^{+}}, \frac{a_{i j}^{L}+\sigma_{i j}^{L}}{\left(a_{i j}^{U}+\sigma_{i j}^{U}\right)^{+}}\right),\right. \\
& \left.\left(\frac{a_{i j}^{U}-\tau_{i j}^{U}}{\left(a_{i j}^{U}+\sigma_{i j}^{U}\right)^{+}}, \frac{a_{i j}^{U}}{\left(a_{i j}^{U}+\sigma_{i j}^{U}\right)^{+}}, \frac{a_{i j}^{U}+\sigma_{i j}^{U}}{\left(a_{i j}^{U}+\sigma_{i j}^{U}\right)^{+}}\right)\right], \\
j & \in \Omega_{b},
\end{aligned}
$$




$$
\begin{aligned}
& \tilde{A}=\left[\left(\left(a_{i j}\right)_{1}^{L}\left(a_{i j}\right)_{2}^{L},\left(a_{i j}\right)_{3}^{L}\right),\left(\left(a_{i j}\right)_{1}^{U}\left(a_{i j}\right)_{2}^{U},\left(a_{i j}\right)_{3}^{U}\right)\right]_{m \times n} \\
& \left.=\left[\begin{array}{ccc}
{\left[\left(\left(a_{11}\right)_{1}^{L}\left(a_{11}\right)_{2}^{L},\left(a_{11}\right)_{3}^{L}\right),\left(\left(a_{11}\right)_{1}^{U}\left(a_{11}\right)_{2}^{U},\left(a_{11}\right)_{3}^{U}\right)\right]} & \cdots & {\left[\left(\left(a_{1 n}\right)_{1}^{L}\left(a_{1 n}\right)_{2}^{L},\left(a_{1 n}\right)_{3}^{L}\right),\left(\left(a_{1 n}\right)_{1}^{U}\left(a_{1 n}\right)_{2}^{U},\left(a_{1 n}\right)_{3}^{U}\right)\right]} \\
\vdots & \ddots & \vdots \\
{\left[\left(\left(a_{m 1}\right)_{1}^{L}\left(a_{m 1}\right)_{2}^{L},\left(a_{m 1}\right)_{3}^{L}\right),\left(\left(a_{m 1}\right)_{1}^{U}\left(a_{m 1}\right)_{2}^{U},\left(a_{m 1}\right)_{3}^{U}\right)\right]} & \cdots & {\left[\left(\left(a_{m n}\right)_{1}^{L}\left(a_{m n}\right)_{2}^{L},\left(a_{m n}\right)_{3}^{L}\right),\left(\left(a_{m n}\right)_{1}^{U}\left(a_{m n}\right)_{2}^{U},\left(a_{m n}\right)_{3}^{U}\right)\right]}
\end{array}\right](8)\right]
\end{aligned}
$$

Box II

and:

$$
\begin{aligned}
\left(\tilde{a}_{i j}^{\prime}\right) & =\left[\left(\left(a_{i j}^{\prime}\right)_{1}^{L},\left(a^{\prime}{ }_{i j}\right)_{2}^{L},\left(a_{i j}^{\prime}\right)_{3}^{L}\right),\right. \\
\left.\left(\left(a_{i j}^{\prime}\right)_{1}^{U},\left(a^{\prime}{ }_{i j}\right)_{2}^{U},\left(a^{\prime}{ }_{i j}\right)_{3}^{U}\right)\right] & \\
= & {\left[\left(\frac{\left(a_{i j}^{U}-\tau_{i j}^{U}\right)^{-}}{a_{i j}^{L}+\sigma_{i j}^{L}}, \frac{\left(a_{i j}^{U}-\tau_{i j}^{U}\right)^{-}}{a_{i j}^{L}}, \frac{\left(a_{i j}^{U}-\tau_{i j}^{U}\right)^{-}}{a_{i j}^{L}-\tau_{i j}^{L}}\right)\right.} \\
& \left.\left(\frac{\left(a_{i j}^{U}-\tau_{i j}^{U}\right)^{-}}{a_{i j}^{U}+\sigma_{i j}^{U}}, \frac{\left(a_{i j}^{U}-\tau_{i j}^{U}\right)^{-}}{a_{i j}^{U}}, \frac{\left(a_{i j}^{U}-\tau_{i j}^{U}\right)^{-}}{a_{i j}^{U}-\tau_{i j}^{U}}\right)\right], \\
j & \in \Omega_{c},
\end{aligned}
$$

where $\Omega_{b}$ and $\Omega_{c}$ are the sets of benefit and cost attributes for MPEP, respectively, $\left(a_{i j}^{U}+\sigma_{i j}^{U}\right)^{+}=$ $\max _{i}\left(a_{i j}^{U}+\sigma_{i j}^{U}\right),\left(a_{i j}^{U}-\tau_{i j}^{U}\right)^{-}=\min _{i}\left(a_{i j}^{U}-\tau_{i j}^{U}\right), i=$ $1, \ldots, m$. For convenience, it is shown as:

$$
\begin{gathered}
{\left[\left(\left(a_{i j}^{\prime}\right)_{1}^{L}\left(a_{i j}^{\prime}\right)_{2}^{L},\left(a_{i j}^{\prime}\right)_{3}^{L}\right),\left(\left(a_{i j}^{\prime}\right)_{1}^{U}\left(a_{i j}^{\prime}\right)_{2}^{U},\left(a_{i j}^{\prime}\right)_{3}^{U}\right)\right]} \\
=\left[\left(a^{\prime}{ }_{i j}^{L}-\tau_{i j}^{\prime L}, a_{i j}^{\prime L}, a_{i j}^{\prime L}+\sigma_{i j}^{\prime L}\right)\right. \\
\left.\left(a_{i j}^{\prime U}-\tau_{i j}^{\prime U}, a_{i j}^{\prime U}, a_{i j}^{\prime U}+\sigma_{i j}^{\prime U}\right)\right]
\end{gathered}
$$

Step 4. Build a PM interval value matrix of MPEP. PM interval values of IVF:

$$
\begin{array}{r}
\tilde{a}_{i j}^{\prime}=\left[\left(a_{i j}^{\prime L}-{\tau^{\prime}}_{i j}^{L}, a_{i j}^{\prime L}, a_{i j}^{\prime L}+{\sigma^{\prime}}_{i j}^{L}\right),\right. \\
\left.\left(a_{i j}^{\prime}-\tau_{i j}^{\prime U}, a_{i j}^{\prime}, a_{i j}^{\prime}+\sigma_{i j}^{\prime}\right)\right],
\end{array}
$$

are determined using Eq. (6):

$$
\begin{aligned}
\bar{m}_{i j} & =\left[m_{i j}^{L}, m_{i j}^{U}\right] \\
& =\left[a^{\prime}{ }_{i j}^{L}+\frac{1}{6}\left({\sigma^{\prime}}_{i j}^{L}-\tau_{i j}^{\prime L}\right), a_{i j}^{\prime U}+\frac{1}{6}\left({\sigma^{\prime}}_{i j}^{U}-\tau_{i j}^{\prime U}\right)\right]_{(11)}
\end{aligned}
$$

PM interval value matrix is built for MPEP as follows:

$$
\bar{M}=\left[\bar{m}_{i j}\right]_{m \times n}=\left[\begin{array}{cccc}
\bar{m}_{11} & \bar{m}_{12} & \ldots & \bar{m}_{1 n} \\
\bar{m}_{21} & \bar{m}_{22} & \ldots & \bar{m}_{2 n} \\
\vdots & \vdots & \ddots & \vdots \\
\bar{m}_{m 1} & \bar{m}_{m 2} & \ldots & \bar{m}_{m n}
\end{array}\right]
$$

Step 5. Build the SD interval value matrix of MPEP. PSD values of IVF:

$$
\begin{gathered}
\tilde{a}_{i j}^{\prime}=\left[\left(a_{i j}^{\prime L}-\tau_{i j}^{\prime L}, a_{i j}^{\prime L}, a_{i j}^{\prime L}+\sigma_{i j}^{\prime L}\right),\right. \\
\left.\left(a_{i j}^{\prime}-\tau_{i j}^{\prime U}, a_{i j}^{\prime U}, a_{i j}^{\prime U}+{\sigma^{\prime}}_{i j}^{U}\right)\right],
\end{gathered}
$$

are given through Eq. (7):

$$
\begin{aligned}
\overline{s d}_{i j} & =\left[s d_{i j}^{L}, s d_{i j}^{U}\right] \\
& =\left[\sqrt{\frac{1}{24}}\left({\sigma^{\prime}}_{i j}^{L}+\tau^{\prime}{ }_{i j}^{L}\right), \sqrt{\frac{1}{24}}\left({\sigma^{\prime}}_{i j}^{U}+\tau_{i j}^{\prime U}\right)\right] .
\end{aligned}
$$

Then, the PSD interval value matrix is constructed for MPEP as follows:

$$
\overline{S D}=\left[\overline{s d}_{i j}\right]_{m \times n}=\left[\begin{array}{cccc}
\overline{s d}_{11} & \overline{s d}_{12} & \ldots & \overline{s d}_{1 n} \\
\overline{s d}_{21} & \overline{s d}_{22} & \ldots & \overline{s d}_{2 n} \\
\vdots & \vdots & \ddots & \vdots \\
\overline{s d}_{m 1} & \overline{s d}_{m 2} & \ldots & \overline{s d}_{m n}
\end{array}\right]
$$


Step 6. Consider positive-ideal and negative-ideal vectors (PIV and NIV) of PM interval values for MPEP.

$$
\begin{aligned}
\bar{M}^{*} & =\left[\left(m_{j}^{*}\right)^{L},\left(m_{j}^{*}\right)^{U}\right]=\left\{\bar{M}_{1}^{*}, \bar{M}_{2}^{*}, \ldots, \bar{M}_{n}^{*}\right\} \\
& =\left\{\max _{i} \bar{m}_{i j} \mid i=1,2, \ldots, m\right\}, \\
\bar{M}^{-} & =\left[\left(m_{j}^{-}\right)^{L},\left(m_{j}^{-}\right)^{U}\right]=\left\{\bar{M}_{1}^{-}, \bar{M}_{2}^{-}, \ldots, \bar{M}_{n}^{-}\right\} \\
& =\left\{\min _{i} \bar{m}_{i j} \mid i=1,2, \ldots, m\right\} .
\end{aligned}
$$

Step 7. Define PIV and NIV of PSD interval values.

$$
\begin{aligned}
\overline{S D}^{*} & =\left[\left(s d_{j}^{*}\right)^{L},\left(s d_{j}^{*}\right)^{U}\right]=\left\{\overline{S D}_{1}^{*},{\overline{S D_{2}}}_{2}^{*}, \ldots,{\overline{S D_{n}}}_{n}^{*}\right\} \\
& =\left\{\min _{i} \overline{s d}_{i j} \mid i=1,2, \ldots, m\right\} \\
\overline{S D} & =\left[\left(s d_{j}^{-}\right)^{L},\left(s d_{j}^{-}\right)^{U}\right]=\left\{{\overline{S D_{1}}}_{1}, \overline{S D_{2}^{-}}, \ldots, \overline{S D_{n}}\right\} \\
& =\left\{\max _{i} \overline{s d}_{i j} \mid i=1,2, \ldots, m\right\} .
\end{aligned}
$$

Step 8. Obtain separation measures of each maintenance policy candidate by PM and PSD interval values from $\operatorname{PIV}\left(\bar{M}^{*}\right.$ and $\left.\overline{S D}^{*}\right)$, respectively.

$$
\begin{aligned}
& D_{i}\left(\bar{m}_{i j}, \overline{M_{j}^{*}}\right) \\
& =\sqrt{\sum_{j=1}^{n} w_{j}\left(\left(\left(m_{j}^{*}\right)^{L}-m_{i j}^{L}\right)^{2}+w_{j}\left(\left(m_{j}^{*}\right)^{U}-m_{i j}^{U}\right)^{2}\right)},(19 \\
& D_{i}\left(\overline{s d}_{i j}, \overline{S D}_{j}^{*}\right) \\
& =\sqrt{\sum_{j=1}^{n}\left(w_{j}\left(\left(\left(s d_{j}^{*}\right)^{L}-s d_{i j}^{L}\right)^{2}+\left(\left(s d_{j}^{*}\right)^{U}-s d_{i j}^{U}\right)^{2}\right)\right)} .
\end{aligned}
$$

Step 9. Obtain separation measures of each maintenance policy by PM and PSD interval values from $\operatorname{NIV}\left(\bar{M}^{-}\right.$and $\left.\overline{S D}_{j}^{-}\right)$, respectively.

$$
\begin{aligned}
& D_{i}\left(\bar{m}_{i j}, \overline{M_{j}^{-}}\right)= \\
& \sqrt{\sum_{j=1}^{n} w_{j}\left(\left(\left(m_{j}^{-}\right)^{L}-m_{i j}^{L}\right)^{2}+\left(\left(m_{j}^{-}\right)^{U}-m_{i j}^{U}\right)^{2}\right)}, \\
& D_{i}\left(\overline{s d}_{i j}, \overline{S D}_{j}^{-}\right)= \\
& \sqrt{\sum_{j=1}^{n} w_{j}\left(\left(\left(s d_{j}^{-}\right)^{L}-s d_{i j}^{L}\right)^{2}+\left(\left(s d_{j}^{-}\right)^{U}-s d_{i j}^{U}\right)^{2}\right)} .
\end{aligned}
$$

Step 10. Compute the proposed new relative coefficient degree for each maintenance policy candidate.

$$
\begin{aligned}
& \psi_{i}^{+}=\sqrt{\frac{D_{i}\left(\bar{m}_{i j}, \bar{M}_{j}^{+}\right) \times D_{i}\left(\overline{s d}_{i j}, \overline{S D}_{j}^{+}\right)}{D_{i}\left(\bar{m}_{i j}, \bar{M}_{j}^{-}\right) \times D_{i}\left(\overline{s d}_{i j}, \overline{S D}_{j}^{-}\right)}}, \\
& \psi_{i}^{-}=\sqrt{\frac{D_{i}\left(\bar{m}_{i j}, \bar{M}_{j}^{-}\right) \times D_{i}\left(\overline{s d}_{i j}, \overline{S D}_{j}^{-}\right)}{D_{i}\left(\bar{m}_{i j}, \bar{M}_{j}^{+}\right) \times D_{i}\left(\overline{s d}_{i j}, \overline{S D}_{j}^{+}\right)}} .
\end{aligned}
$$

Step 11. Calculate the proposed closeness coefficient $C I_{i}$ for MPEP.

$$
C I_{i}=\frac{\psi_{i}^{-}}{\psi_{i}^{-}+\psi_{i}^{+}}
$$

Step 12. Rank each maintenance policy candidate based on the values $C I_{i}$.

Step 13. Perform an analysis of Monte Carlo simulation and then, rank the maintenance policy candidates based on their $C I_{i}$ values.

\section{Case study}

In this section, the MPEP is investigated in a manufacturing company in Iran from the perspective of RE. The steps of the introduced model are provided and computational results are presented in this case study for manufacturing systems with Monte Carlo simulation. Five maintenance policies are reviewed and the best policy among potential policy candidates is evaluated and selected on the basis of eleven evaluation criteria including $\mathrm{RE}$ factors based on safety and risk concepts. These five maintenance policies are FBM, PM, CBM, TPM, and TQMain.

The explanations of all the five maintenance policies and eleven evaluation criteria are presented in the following subsections.

\subsection{Maintenance policy approaches}

Maintenance policy or procedure involves arrangement of planning and decisions for the identification of faults, inquiry about causes, and execution phase of numerous inspections along with replacing devices or parts and repairing them. Five major maintenance policies are described as follows:

- Failure-Based Maintenance (FBM) $\left(A_{1}\right)$ is regarded as a maintenance policy that is adopted only when a failure or breakdown occurs. In the FBM approach, just repair or substitution responses are made; however, no response is given to identify the cause of failure or to hinder it $[63,64]$;

- Preventive Maintenance (PvM) $\left(A_{2}\right)$ can be characterized as a movement that has been attempted frequently at pre-chosen intervals on a regular basis 
$[65,66]$, while the part or device properly operates to lessen the gathered deterioration, while repair is the action that involves transfering a device or part to a non-failed state upon encountering a failure [67];

- Based on Condition-Based Maintenance (CBM) policy $\left(A_{3}\right)$, each of the main activities after every inspection relies on the condition of a plant or system. There is no activity or negligible activity to introduce to the framework in the same class prior to corruption. In addition, there is no essential maintenance to transfer the system to a condition equivalent to another system. This policy depends on deterministic and probabilistic models [67];

- Total Productive Maintenance (TPM) $\left(A_{4}\right)$ aims to present a comprehensive methodology to accomplish a standard for executions in production versus overall effectiveness of equipment, machines, and processes $[68,69]$. The TPM enhances the overall effectiveness of equipment for all times by considering the dynamic contribution of operators [70];

- Total Quality Maintenance (TQMain) $\left(A_{5}\right)$ can be characterized as the policy of maintenance for a plant or a system that focuses on genuine utilization of real-time data so as to detect the causes of failure through proper evaluation and to change or modify the machine state regarding the information to control and monitor damage at an early stage to suggest a quality item to a client at opportune time $[63,71]$.

\subsection{Selection criteria}

The main criteria associated with the problem, i.e., MPEP, based on safety and risk concepts include the qualities, skills, and capabilities of a system with a particular focus on the RE, which can demonstrate the given task effectively. Notably, flexibility, fault tolerance, redundancy, and awareness are introduced as important factors of RE [72-75]. Brief explanations of all these main criteria based on safety and risk concepts are provided as follows (e.g., $[41,46])$ :

- Capital cost $\left(C_{1}\right)$ is a significant factor that focuses on the fixed cost;
- Running cost $\left(C_{2}\right)$ is another significant factor that focuses on the variable cost to properly implement the maintenance policy;

- Awareness $\left(C_{3}\right)$ is one of the important factors of RE. Gathered information gives this plausibility for the maintenance administration to ensure greater awareness of what occurs in a manufacturing system or plant;

- Redundancy $\left(C_{4}\right)$ is a significant factor in RE and is considered as the ability of a manufacturing system or plant to perform quite well for an unknown period;

- Fault tolerance $\left(C_{5}\right)$ is a standout factor of RE amongst the most enhanced tools and techniques for enhancing safety as well as the reliability of a manufacturing plant or system;

- Repair load $\left(C_{6}\right)$ is an evaluation factor that points to the ratio of repair resources to manufacturing resources and states the traffic density regarding the repair process;

- Operator skill $\left(C_{7}\right)$ is an evaluation factor that demonstrates which maintenance policy has skilled workforce;

- Flexibility $\left(C_{8}\right)$ is one of the important factors of $\mathrm{RE}$ and is regarded as the ability of a manufacturing system or plant to make quick modifications;

- Efficiency $\left(C_{9}\right)$ is an assessment factor that illustrates how a production system or plant works efficiently;

- Facility utilization $\left(C_{10}\right)$ is an assessment factor that illustrates all the repair facilities utilized in a suitable way;

- Resource availability $\left(C_{11}\right)$ is an evaluation factor that relates to the availability of repair workforce at the time of maintenance.

\subsection{Computational results}

In this case study of the decision problem, linguistic variables are reported for rating, as given in Table 2 . Then, evaluation of the weights and ratings is given in Table 3. Weights of evaluation policy criteria including $\mathrm{RE}$ factors based on safety and risk concepts are given below:

Table 2. Linguistic variables for the values of maintenance policy candidates.

\begin{tabular}{ll}
\hline Linguistic variables & \multicolumn{1}{c}{ Interval-valued fuzzy numbers } \\
\hline Very poor & {$[(0.00,0.00,2.00),(0.00,0.00,3.50)]$} \\
Poor & {$[(1.00,2.50,4.00),(0.00,2.50,6.00)]$} \\
Fair & {$[(3.50,5.00,6.50),(2.00,5.00,8.00)]$} \\
Good & {$[(6.00,7.50,9.00),(4.00,7.50,10.00)]$} \\
Very good & {$[(8.00,10.00,10.00),(6.50,10.00,10.00)]$} \\
\hline
\end{tabular}


Table 3. Interval-valued fuzzy matrix of eleven criteria for maintenance policy evaluation problem.

\begin{tabular}{|c|c|c|c|c|}
\hline \multirow[b]{2}{*}{$\begin{array}{c}\text { Maintenance } \\
\text { policy candidates }\end{array}$} & \multicolumn{4}{|c|}{ Eleven criteria } \\
\hline & Capital cost & Running cost & Awareness & Redundancy \\
\hline FBM & 1.10 & 2.00 & $\begin{array}{r}{[(1.00,2.50,4.00),} \\
(0.00,2.50,6.00)]\end{array}$ & $\begin{array}{c}{[(0.00,0.00,2.00),} \\
(0.00,0.00,3.50)]\end{array}$ \\
\hline PvM & 1.90 & 1.50 & $\begin{array}{c}{[(3.50,5.00,6.50),} \\
(2.00,5.00,8.00)]\end{array}$ & $\begin{array}{l}{[(6.00,7.50,9.00),} \\
(4.00,7.50,10.00)]\end{array}$ \\
\hline $\mathrm{CBM}$ & 1.60 & 1.40 & $\begin{array}{r}{[(3.50,5.00,6.50),} \\
(2.00,5.00,8.00)]\end{array}$ & $\begin{array}{c}{[(3.50,5.00,6.50)} \\
(2.00,5.00,8.00)]\end{array}$ \\
\hline TPM & 3.00 & 1.20 & $\begin{array}{r}{[(3.50,5.00,6.50),} \\
(2.00,5.00,8.00)]\end{array}$ & $\begin{array}{l}{[(6.00,7.50,9.00)} \\
(4.00,7.50,10.00)]\end{array}$ \\
\hline \multirow[t]{2}{*}{ TQMain } & 3.30 & 1.30 & $\begin{array}{l}{[(6.00,7.50,9.00),} \\
(4.00,7.50,10.00)]\end{array}$ & $\begin{array}{l}{[(8.00,10.00,10.00),} \\
(6.50,10.00,10.00)]\end{array}$ \\
\hline & Fault-tolerant & Repair load & Operator skill & Flexibility \\
\hline FBM & $\begin{array}{l}{[(3.50,5.00,6.50),} \\
(2.00,5.00,8.00)]\end{array}$ & $\begin{array}{r}{[(3.50,5.00,6.50),} \\
(2.00,5.00,8.00)]\end{array}$ & $\begin{array}{l}{[(6.00,7.50,9.00),} \\
(4.00,7.50,10.00)]\end{array}$ & $\begin{array}{r}{[(0.00,0.00,2.00),} \\
(0.00,0.00,3.50)]\end{array}$ \\
\hline PvM & $\begin{array}{l}{[(6.00,7.50,9.00),} \\
(4.00,7.50,10.00)]\end{array}$ & $\begin{array}{l}{[(6.00,7.50,9.00),} \\
(4.00,7.50,10.00)]\end{array}$ & $\begin{array}{l}{[(6.00,7.50,9.00),} \\
(4.00,7.50,10.00)]\end{array}$ & $\begin{array}{r}{[(0.00,0.00,2.00),} \\
(0.00,0.00,3.50)]\end{array}$ \\
\hline $\mathrm{CBM}$ & $\begin{array}{l}{[(6.00,7.50,9.00)} \\
(4.00,7.50,10.00)]\end{array}$ & $\begin{array}{l}{[(6.00,7.50,9.00),} \\
(4.00,7.50,10.00)]\end{array}$ & $\begin{array}{c}{[(3.50,5.00,6.50)} \\
(2.00,5.00,8.00)]\end{array}$ & $\begin{array}{l}{[(6.00,7.50,9.00),} \\
(4.00,7.50,10.00)]\end{array}$ \\
\hline TPM & $\begin{array}{c}{[(8.00,10.00,10.00),} \\
(6.50,10.00,10.00)]\end{array}$ & $\begin{array}{r}{[(8.00,10.00,10.00),} \\
(6.50,10.00,10.00)]\end{array}$ & $\begin{array}{c}{[(8.00,10.00,10.00),} \\
(6.50,10.00,10.00)]\end{array}$ & $\begin{array}{r}{[(3.50,5.00,6.50),} \\
(2.00,5.00,8.00)]\end{array}$ \\
\hline \multirow[t]{2}{*}{ TQMain } & $\begin{array}{r}{[(8.00,10.00,10.00),} \\
(6.50,10.00,10.00)]\end{array}$ & $\begin{array}{r}{[(8.00,10.00,10.00),} \\
(6.50,10.00,10.00)]\end{array}$ & $\begin{array}{l}{[(6.00,7.50,9.00),} \\
(4.00,7.50,10.00)]\end{array}$ & $\begin{array}{c}{[(1.00,2.50,4.00),} \\
(0.00,2.50,6.00)]\end{array}$ \\
\hline & Efficiency & $\begin{array}{c}\text { Facility } \\
\text { utilization }\end{array}$ & $\begin{array}{c}\text { Resource } \\
\text { availability }\end{array}$ & \\
\hline FBM & $\begin{array}{c}{[(0.00,0.00,2.00),} \\
(0.00,0.00,3.50)]\end{array}$ & $\begin{array}{c}{[(0.00,0.00,2.00),} \\
(0.00,0.00,3.50)]\end{array}$ & $\begin{array}{l}{[(6.00,7.50,9.00),} \\
(4.00,7.50,10.00)]\end{array}$ & \\
\hline PvM & $\begin{array}{r}{[(3.50,5.00,6.50),} \\
(2.00,5.00,8.00)]\end{array}$ & $\begin{array}{r}{[(0.00,0.00,2.00),} \\
(0.00,0.00,3.50)]\end{array}$ & $\begin{array}{c}{[(3.50,5.00,6.50),} \\
(2.00,5.00,8.00)]\end{array}$ & \\
\hline $\mathrm{CBM}$ & $\begin{array}{c}{[(3.50,5.00,6.50)} \\
(2.00,5.00,8.00)]\end{array}$ & $\begin{array}{r}{[(1.00,2.50,4.00)} \\
(0.00,2.50,6.00)]\end{array}$ & $\begin{array}{c}{[(3.50,5.00,6.50)} \\
(2.00,5.00,8.00)]\end{array}$ & \\
\hline TPM & $\begin{array}{r}{[(8.00,10.00,10.00),} \\
(6.50,10.00,10.00)]\end{array}$ & $\begin{array}{l}{[(6.00,7.50,9.00),} \\
(4.00,7.50,10.00)]\end{array}$ & $\begin{array}{l}{[(6.00,7.50,9.00),} \\
(4.00,7.50,10.00)]\end{array}$ & \\
\hline TQMain & $\begin{array}{c}{[(8.00,10.00,10.00),} \\
(6.50,10.00,10.00)]\end{array}$ & $\begin{array}{c}{[(3.50,5.00,6.50)} \\
(2.00,5.00,8.00)]\end{array}$ & $\begin{array}{c}{[(3.50,5.00,6.50)} \\
(2.00,5.00,8.00)]\end{array}$ & \\
\hline
\end{tabular}

Notes: FBM: Failure-Based Maintenance; PvM: Preventive Maintenance; CBM: Condition-Based Maintenance; TPM: Total Productive Maintenance; TQMain: Total Quality Maintenance.

$W=\{0.112,0.112,0.091,0.100,0.091,0.071,0.083$

$$
0.071,0.078\}
$$

The IVF matrix is transformed into a normalized matrix of maintenance policy candidates, as given in Table 4. Then, IV-PM and IV-SD matrices of the MPEP are reported in Tables 5 and 6 .

Then, PIV and NIV of IV-PM as well as PIV and NIV of IV-PSD are given for MPEP. Consequently, the separation measures of each maintenance policy candidate's IV-PM and IV-PSD from the PIV $\left(\bar{M}^{*}\right.$ and $\left.\overline{S D}^{*}\right)$ and the NIV $(\bar{M}$ and $\overline{S D}$ ) are calculated, respectively. Finally, Table 7 shows $C I_{i}$ values based on the proposed new relative coefficient degrees for maintenance policy options. Comparative analysis among the recent fuzzy decision methods through ranking of each policy for MPEP is also given in this table.

Following 5000 simulation runs, related distributions of $C I_{i}$ for each maintenance policy candidate are provided to make the best decision regarding this policy evaluation and selection problem; the computational results are depicted in Figure 2. This figure illustrates the corresponding histogram for each distribution of $C I_{i}$ for every maintenance policy alternative or candi- 
Table 4. Normalized interval-valued fuzzy decision matrix for maintenance policy evaluation problem.

\begin{tabular}{|c|c|c|c|c|}
\hline \multirow[b]{2}{*}{$\begin{array}{c}\text { Maintenance } \\
\text { policy candidates }\end{array}$} & \multicolumn{4}{|c|}{ Eleven criteria } \\
\hline & Capital cost & Running cost & Awareness & Redundancy \\
\hline FBM & $\begin{array}{c}{[(1.000,1.000,1.000),} \\
(1.000,1.000,1.000)]\end{array}$ & $\begin{array}{c}{[(0.588,0.588,0.588)} \\
0.588,0.588,0.588)]\end{array}$ & $\begin{array}{c}{[(0.100,0.250,0.400)} \\
(0.000,0.250,0.600)]\end{array}$ & $\begin{array}{r}{[(0.000,0.000,0.200),} \\
(0.000,0.000,0.350)]\end{array}$ \\
\hline PvM & $\begin{array}{l}{[(0.563,0.563,0.563)} \\
(0.563,0.563,0.563)]\end{array}$ & $\begin{array}{c}{[(0.769,0.769,0.769)} \\
0.769,0.769,0.769)]\end{array}$ & $\begin{array}{r}{[(0.350,0.500,0.650)} \\
(0.200,0.500,0.800)]\end{array}$ & $\begin{array}{r}{[(0.600,0.750,0.900),} \\
(0.400,0.750,1.000)]\end{array}$ \\
\hline $\mathrm{CBM}$ & $\begin{array}{l}{[(0.643,0.643,0.643),} \\
(0.643,0.643,0.643)]\end{array}$ & $\begin{array}{c}{[(0.833,0.833,0.833)} \\
0.833,0.833,0.833)]\end{array}$ & $\begin{array}{c}{[(0.350,0.500,0.650)} \\
(0.200,0.500,0.800)]\end{array}$ & $\begin{array}{c}{[(0.350,0.500,0.650),} \\
(0.200,0.500,0.800)]\end{array}$ \\
\hline TPM & $\begin{array}{l}{[(0.346,0.346,0.346),} \\
(0.346,0.346,0.346,)]\end{array}$ & $\begin{array}{c}{[(1.000,1.000,1.000)} \\
1.000,1.000,1.000)]\end{array}$ & $\begin{array}{c}{[(0.350,0.500,0.650)} \\
(0.200,0.500,0.800)]\end{array}$ & $\begin{array}{r}{[(0.600,0.750,0.900),} \\
(0.400,0.750,1.000)]\end{array}$ \\
\hline \multirow[t]{2}{*}{ TQMain } & $\begin{array}{l}{[(0.321,0.321,0.321)} \\
(0.321,0.321,0.321)]\end{array}$ & $\begin{array}{c}{[(0.909,0.909,0.909)} \\
0.909,0.909,0.909)]\end{array}$ & $\begin{array}{c}{[(0.600,0.750,0.900)} \\
(0.400,0.750,1.000)]\end{array}$ & $\begin{array}{r}{[(0.800,1.000,1.000),} \\
(0.650,1.000,1.000)]\end{array}$ \\
\hline & Fault-tolerant & Repair load & Operator skill & Flexibility \\
\hline FBM & $\begin{array}{c}{[(0.350,0.500,0.650)} \\
(0.200,0.500,0.800)]\end{array}$ & $\begin{array}{c}{[(0.308,0.400,0.571)} \\
(0.250,0.400,1.000)]\end{array}$ & $\begin{array}{c}{[(0.600,0.750,0.900)} \\
(0.400,0.750,1.000)]\end{array}$ & $\begin{array}{r}{[(0.000,0.000,0.200),} \\
(0.000,0.000,0.350)]\end{array}$ \\
\hline PvM & $\begin{array}{c}{[(0.600,0.750,0.900)} \\
(0.400,0.750,1.000)]\end{array}$ & $\begin{array}{c}{[(0.222,0.267,0.333)} \\
(0.200,0.267,0.500)]\end{array}$ & $\begin{array}{c}{[(0.600,0.750,0.900)} \\
(0.400,0.750,1.000)]\end{array}$ & $\begin{array}{r}{[(0.000,0.000,0.200),} \\
(0.000,0.000,0.350)]\end{array}$ \\
\hline $\mathrm{CBM}$ & $\begin{array}{c}{[(0.600,0.750,0.900)} \\
(0.400,0.750,1.000)]\end{array}$ & $\begin{array}{c}{[(0.222,0.267,0.333)} \\
(0.200,0.267,0.500)]\end{array}$ & $\begin{array}{c}{[(0.350,0.500,0.650)} \\
(0.200,0.500,0.800)]\end{array}$ & $\begin{array}{c}{[(0.600,0.750,0.900),} \\
(0.400,0.750,1.000)]\end{array}$ \\
\hline TPM & $\begin{array}{c}{[(0.800,1.000,1.000),} \\
(0.650,1.000,1.000)]\end{array}$ & $\begin{array}{c}{[(0.200,0.200,0.250)} \\
(0.200,0.200,0.308)]\end{array}$ & $\begin{array}{c}{[(0.800,1.000,1.000)} \\
(0.650,1.000,1.000)]\end{array}$ & $\begin{array}{c}{[(0.350,0.500,0.650),} \\
(0.200,0.500,0.800)]\end{array}$ \\
\hline \multirow[t]{2}{*}{ TQMain } & $\begin{array}{c}{[(0.800,1.000,1.000),} \\
(0.650,1.000,1.000)]\end{array}$ & $\begin{array}{c}{[(0.200,0.200,0.250)} \\
(0.200,0.200,0.308)]\end{array}$ & $\begin{array}{c}{[(0.600,0.750,0.900)} \\
(0.400,0.750,1.000)]\end{array}$ & $\begin{array}{c}{[(0.100,0.250,0.400),} \\
(0.000,0.250,0.600)]\end{array}$ \\
\hline & Efficiency & Facility utilization & Resource availability & \\
\hline FBM & $\begin{array}{c}{[(0.000,0.000,0.200),} \\
(0.000,0.000,0.350)]\end{array}$ & $\begin{array}{c}{[(0.000,0.000,0.200)} \\
(0.000,0.000,0.350)]\end{array}$ & $\begin{array}{c}{[(0.600,0.750,0.900)} \\
(0.400,0.750,1.000)]\end{array}$ & \\
\hline PvM & $\begin{array}{c}{[(0.350,0.500,0.650)} \\
(0.200,0.500,0.800)]\end{array}$ & $\begin{array}{c}{[(0.350,0.500,0.650)} \\
(0.200,0.500,0.800)]\end{array}$ & $\begin{array}{c}{[(0.350,0.500,0.650),} \\
(0.200,0.500,0.800)]\end{array}$ & \\
\hline $\mathrm{CBM}$ & $\begin{array}{c}{[(0.350,0.500,0.650)} \\
(0.200 .0 .500 .0 .800)]\end{array}$ & $\begin{array}{c}{[(0.350,0.500,0.650)} \\
(0.200 .0 .500 .0 .800)]\end{array}$ & $\begin{array}{c}{[(0.350,0.500,0.650)} \\
(0.200,0.500,0.800)]\end{array}$ & \\
\hline $\mathrm{TPM}$ & $\begin{array}{c}{[(0.800,1.000,1.000),} \\
(0.650,1.000,1.000)]\end{array}$ & $\begin{array}{c}{[(0.800,1.000,1.000)} \\
(0.650,1.000,1.000)]\end{array}$ & $\begin{array}{c}{[(0.600,0.750,0.900),} \\
(0.400,0.750,1.000)]\end{array}$ & \\
\hline TQMain & $\begin{array}{c}{[(0.800,1.000,1.000),} \\
(0.650,1.000,1.000)]\end{array}$ & $\begin{array}{c}{[(0.800,1.000,1.000)} \\
(0.650,1.000,1.000)]\end{array}$ & $\begin{array}{c}{[(0.350,0.500,0.650),} \\
(0.200,0.500,0.800)]\end{array}$ & \\
\hline
\end{tabular}

Notes: FBM: Failure-Based Maintenance, PvM: Preventive Maintenance; CBM: Condition-Based Maintenance; TPM: Total Productive Maintenance; TQMain: Total Quality Maintenance.

date. Final rankings of the maintenance policies from best to worst are as follows:

$$
A_{4}>A_{5}>A_{3}>A_{2}>A_{1} \text {. }
$$

\subsection{Discussion of results}

In this subsection, this paper conducts a sensitivity analysis to further study the impact of weights of four specific selection criteria of the RE for MPEP on final ranking. Results are given in Table 8. Assessments are done by replacing each importance of four RE factors with another importance. Some combinations of these determining factors need to be examined. It is suggested that positioning of the maintenance policy candidates be robust enough. It is worth mentioning that a robust decision-making approach through IVF sets, PSCs, and Monte Carlo simulation is employed to evaluate the uncertain process of decision-making. In addition, Table 7 and Figure 3 show the standard deviation measure considered for maintenance policy candidates to present the scattering space of positioning qualities. The standard deviation measure could push specialists to effortlessly choose the best maintenance policy among the various up-and-comers in an uncertain situation. In doing so, the proposed IVFdecision-making model with PSCs and Monte Carlo simulation has a better quality deviation with respect 
Table 5. Interval valued possibilistic mean values for each maintenance policy.

\begin{tabular}{ccccc}
\hline & \multicolumn{4}{c}{ Eleven criteria } \\
\cline { 2 - 5 } Maintenance \\
\cline { 2 - 5 } policy candidates & Capital cost & Running cost & Awareness & Redundancy \\
\hline FBM & {$[1.000000,1.000000]$} & {$[0.588235,0.588235]$} & {$[0.588235,0.588235]$} & {$[0.033333,0.058333]$} \\
PvM & {$[0.562500,0.562500]$} & {$[0.769231,0.769231]$} & {$[0.769231,0.769231]$} & {$[0.750000,0.733333]$} \\
CBM & {$[0.642857,0.642857]$} & {$[0.833333,0.833333]$} & {$[0.833333,0.833333]$} & {$[0.500000,0.500000]$} \\
TPM & {$[0.346154,0.346154]$} & {$[1.000000,1.000000]$} & {$[1.000000,1.000000]$} & {$[0.750000,0.733333]$} \\
TQMain & {$[0.321429,0.321429]$} & {$[0.909091,0.909091]$} & {$[0.909091,0.909091]$} & {$[0.966667,0.941667]$} \\
\hline & Fault-tolerant & Repair load & Operator skill & Flexibility \\
\hline FBM & {$[0.500000,0.500000]$} & {$[0.413187,0.475000]$} & {$[0.750000,0.733333]$} & {$[0.033333,0.058333]$} \\
PvM & {$[0.750000,0.733333]$} & {$[0.270370,0.294444]$} & {$[0.750000,0.733333]$} & {$[0.033333,0.058333]$} \\
CBM & {$[0.750000,0.733333]$} & {$[0.270370,0.294444]$} & {$[0.500000,0.500000]$} & {$[0.750000,0.733333]$} \\
TPM & {$[0.966667,0.941667]$} & {$[0.208333,0.217949]$} & {$[0.966667,0.941667]$} & {$[0.500000,0.500000]$} \\
TQMain & {$[0.966667,0.941667]$} & {$[0.208333,0.217949]$} & {$[0.750000,0.733333]$} & {$[0.250000,0.266667]$} \\
\hline FBM & Efficiency & Facility utilization & Resource availability & - \\
\hline PvM & {$[0.033333,0.058333]$} & {$[0.033333,0.058333]$} & {$[0.750000,0.733333]$} & - \\
CBM & {$[0.500000,0.500000]$} & {$[0.033333,0.058333]$} & {$[0.500000,0.500000]$} & - \\
TPM & {$[0.500000,0.500000]$} & {$[0.250000,0.266667]$} & {$[0.500000,0.500000]$} & - \\
TQMain & {$[0.966667,0.941667]$} & {$[0.500000,0.500000]$} & {$[0.500000,0.500000]$} & - \\
\hline
\end{tabular}

Notes: FBM: Failure-Based Maintenance; PvM: Preventive Maintenance; CBM: Condition-Based Maintenance; TPM: Total Productive Maintenance; TQMain: Total Quality Maintenance.

Table 6. Interval valued possibilistic standard deviation values for each maintenance policy.

\begin{tabular}{ccccc}
\hline \multirow{2}{*}{$\begin{array}{c}\text { Maintenance } \\
\text { policy candidates }\end{array}$} & Capital cost & Running cost & Awareness & Redundancy \\
\cline { 2 - 5 } & {$[0.000000,0.000000]$} & {$[0.000000,0.000000]$} & {$[0.061237,0.122474]$} & {$[0.040825,0.071443]$} \\
FBM & {$[0.000000,0.000000]$} & {$[0.000000,0.000000]$} & {$[0.061237,0.122474]$} & {$[0.061237,0.122474]$} \\
PvM & {$[0.000000,0.000000]$} & {$[0.000000,0.000000]$} & {$[0.061237,0.122474]$} & {$[0.061237,0.122474]$} \\
TPM & {$[0.000000,0.000000]$} & {$[0.000000,0.000000]$} & {$[0.061237,0.122474]$} & {$[0.061237,0.122474]$} \\
TQMain & {$[0.000000,0.000000]$} & {$[0.000000,0.000000]$} & {$[0.061237,0.122474]$} & {$[0.040825,0.071443]$} \\
\hline FBM & {$[0.061237,0.122474]$} & {$[0.053835,0.153093]$} & {$[0.061237,0.122474]$} & {$[0.040825,0.071443]$} \\
PvM & {$[0.061237,0.122474]$} & {$[0.022680,0.061237]$} & {$[0.061237,0.122474]$} & {$[0.040825,0.071443]$} \\
CBM & {$[0.061237,0.122474]$} & {$[0.022680,0.061237]$} & {$[0.061237,0.122474]$} & {$[0.061237,0.122474]$} \\
TPM & {$[0.040825,0.071443]$} & {$[0.010206,0.021983]$} & {$[0.040825,0.071443]$} & {$[0.061237,0.122474]$} \\
TQMain & {$[0.040825,0.071443]$} & {$[0.010206,0.021983]$} & {$[0.061237,0.122474]$} & {$[0.061237,0.122474]$} \\
\hline FBM & Efficiency & Facility utilization & Resource availability & - \\
\hline PvM & {$[0.040825,0.071443]$} & {$[0.040825,0.071443]$} & {$[0.061237,0.122474]$} & Flexibility \\
CBM & {$[0.061237,0.122474]$} & {$[0.040825,0.071443]$} & {$[0.061237,0.122474]$} & - \\
TPM & {$[0.061237,0.122474]$} & {$[0.061237,0.122474]$} & {$[0.061237,0.122474]$} & - \\
TQMain & {$[0.040825,0.071443]$} & {$[0.061237,0.122474]$} & {$[0.061237,0.122474]$} & - \\
\hline
\end{tabular}

Notes: FBM: Failure-Based Maintenance; PvM: Preventive Maintenance; CBM: Condition-Based Maintenance; TPM: Total Productive Paintenance; TQMain: Total quality maintenance. 
Table 7. Comparative analysis among the recent fuzzy decision methods based on the ranking of each policy for the maintenance policy evaluation problem.

\begin{tabular}{|c|c|c|c|c|c|c|}
\hline \multirow[t]{2}{*}{$\begin{array}{l}\text { Maintenance } \\
\text { policy } \\
\text { candidates }\end{array}$} & \multicolumn{2}{|c|}{$\begin{array}{l}\text { Ranking by proposed } \\
\text { new interval valued } \\
\text { fuzzy decision-making } \\
\text { model with Monte } \\
\text { Carlo simulation }\end{array}$} & \multicolumn{2}{|c|}{$\begin{array}{c}\text { Ranking by Chen [76] } \\
\text { interval valued fuzzy } \\
\text { simple additive } \\
\text { weighting method }\end{array}$} & \multicolumn{2}{|c|}{$\begin{array}{c}\text { Ranking by Chan } \\
\text { and Prakash }[41] \\
\text { fuzzy distance-based method }\end{array}$} \\
\hline & $C l_{i}$ & Ranking & Score & Ranking & $\boldsymbol{R}_{P i}$ & Ranking \\
\hline FBM & 0.301993 & 5 & 0.469 & 5 & 0.45 & 5 \\
\hline PvM & 0.474194 & 4 & 0.544 & 4 & 0.61 & 4 \\
\hline $\mathrm{CBM}$ & 0.532367 & 3 & 0.576 & 3 & 0.66 & 3 \\
\hline TPM & 0.679232 & 1 & 0.694 & 1 & 0.75 & 1 \\
\hline TQMain & 0.646888 & 2 & 0.653 & 2 & 0.73 & 2 \\
\hline $\begin{array}{l}\text { The standard } \\
\text { deviation of } \\
\text { the scores }\end{array}$ & & 0.151 & & 0.089 & 0.120 & \\
\hline
\end{tabular}

Notes: FBM: Failure-Based Maintenance; PvM: Preventive Maintenance; CBM: Condition-Based Maintenance;

TPM: Total Productive Maintenance; TQMain: Total Quality Maintenance.

Table 8. Analysis of the importance of four resilient engineering factors in the maintenance policy evaluation problem.

\begin{tabular}{|c|c|c|c|c|c|c|c|c|c|}
\hline \multirow[b]{2}{*}{ Conditions } & \multicolumn{4}{|c|}{ Resilience engineering factors' weights } & \multicolumn{5}{|c|}{ Maintenance policy options' values } \\
\hline & Awareness & Redundancy & Fault-tolerant & Flexibility & FBM & PvM & CBM & TPM & TQMain \\
\hline Main & 0.091 & 0.100 & 0.100 & 0.071 & 0.302 & 0.474 & 0.532 & 0.679 & 0.647 \\
\hline 1 & 0.100 & 0.091 & 0.100 & 0.071 & 0.304 & 0.468 & 0.532 & 0.677 & 0.644 \\
\hline 2 & 0.100 & 0.100 & 0.091 & 0.071 & 0.302 & 0.474 & 0.532 & 0.678 & 0.647 \\
\hline 3 & 0.071 & 0.100 & 0.100 & 0.091 & 0.299 & 0.465 & 0.544 & 0.682 & 0.641 \\
\hline 4 & 0.091 & 0.100 & 0.100 & 0.071 & 0.302 & 0.474 & 0.532 & 0.679 & 0.647 \\
\hline 5 & 0.091 & 0.071 & 0.100 & 0.100 & 0.306 & 0.441 & 0.548 & 0.675 & 0.628 \\
\hline 6 & 0.091 & 0.100 & 0.071 & 0.100 & 0.297 & 0.459 & 0.547 & 0.678 & 0.638 \\
\hline 7 & 0.091 & 0.100 & 0.100 & 0.071 & 0.302 & 0.474 & 0.532 & 0.679 & 0.647 \\
\hline
\end{tabular}

Notes: FBM: Failure-Based Maintenance; PvM: Preventive Maintenance, CBM: Condition-Based Maintenance;

TPM: Total Productive Maintenance, TQMain: Total Quality Maintenance.

to four different maintenance policies than two decision methods: the fuzzy distance-based method of Chan and Prakash [41] and IVF-SAW method of Chen [76].

\section{Conclusions}

Evaluating and apprising maintenance policy among options in systems or plants is a crucial issue for maintenance managers. It is a challenging task because several conflicting criteria and maintenance policy approaches need to be considered simultaneously. This research introduced a new IVF-decision model via similarity to ideal solutions with Monte Carlo simulation for evaluating the maintenance policies. The model was presented under uncertain conditions in manufacturing systems or plants using a new analysis based on fuzzy
Possibilistic Statistical Concepts (PSCs). Two IVF$\mathrm{PM}$ and SD matrices were introduced. Consequently, novel separation measures were introduced for the maintenance policy selection problem regarding two high Possibilistic Mean (PM) values and low Possibilistic Standard Deviation (PSD) with IVF setting. Finally, a new IVF-distinguished index was extended based on PSCs to determine preference order of all maintenance policy candidates. This research considered Resilience Engineering (RE) factors in addition to conventional assessment criteria for this policy selection problem. Moreover, this research provided a case study in the manufacturing industry to appraise the maintenance policy options under IVF-environment. The comparative analysis among the recent fuzzy decision methods was reported. A sensitivity analysis was 


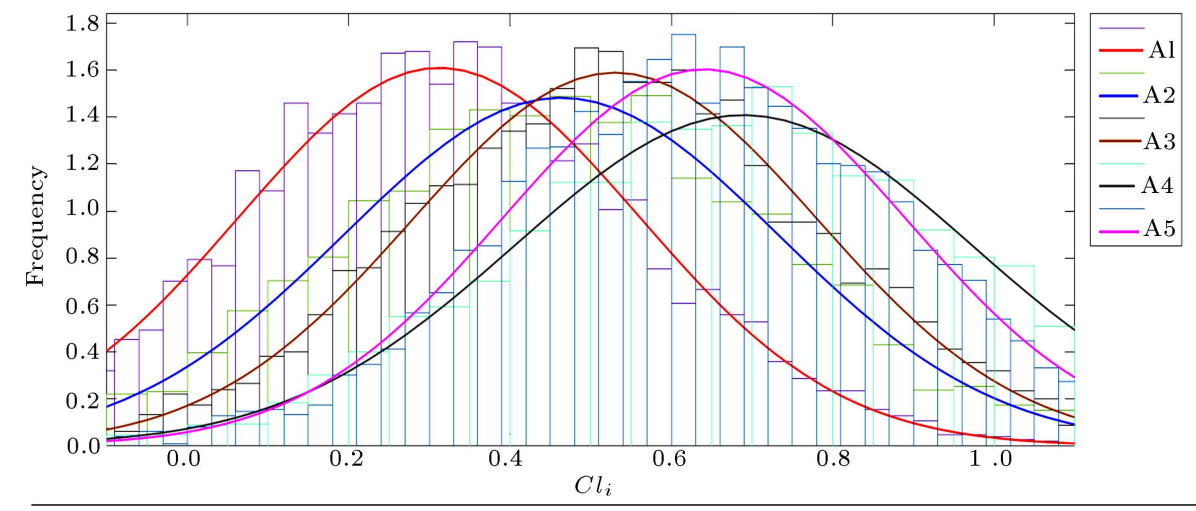

FBM: Failure-Based Maintenance (A1); PvM: Preventive Maintenance (A2);

CBM: Condition-Based Maintenance (A3); TPM: Total Productive Maintenance (A4);

TQMain: Total Quality Maintenance (A5).

Figure 2. Charts of the proposed new closeness coefficient $C l_{i}$ for the maintenance policy evaluation problem.

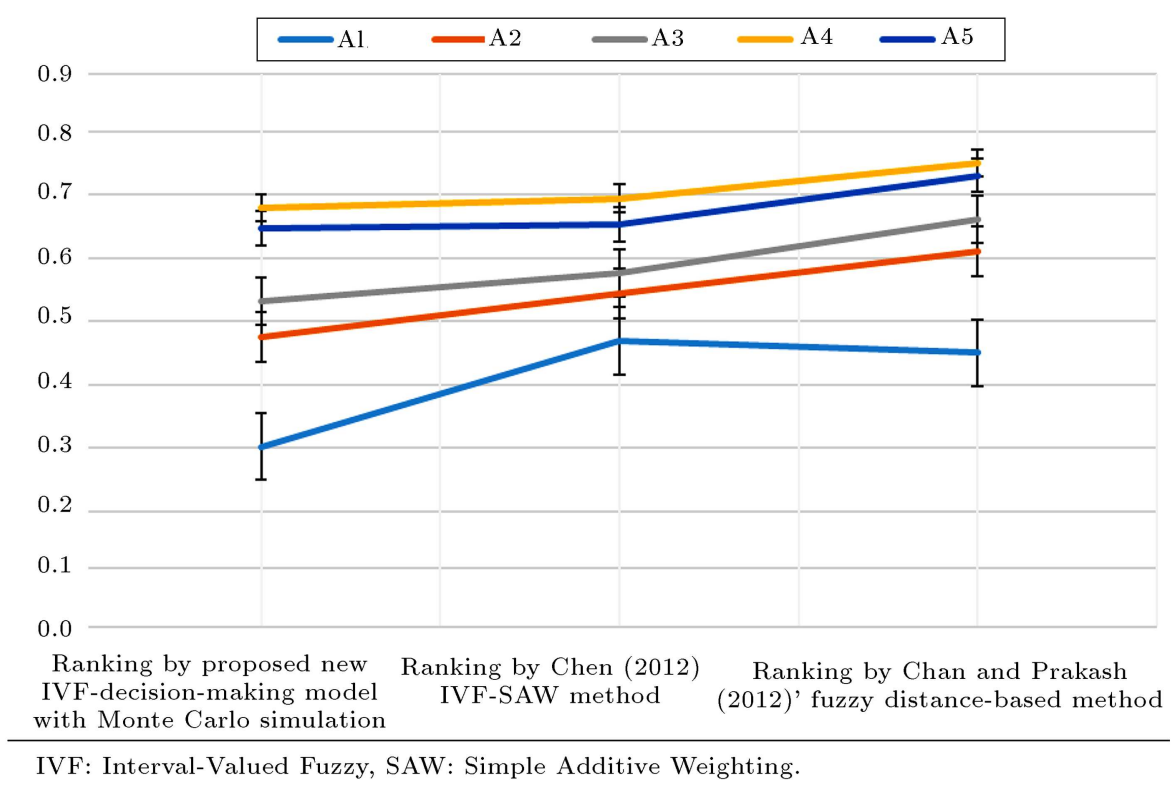

Figure 3. Comparison of the scattering of the proposed method and other two decision methods on the rating of different maintenance policies.

also conducted to investigate the impacts of weights of four main RE factors on the final ranking for the maintenance policy selection problem.

\section{Acknowledgments}

The authors express their gratitude to reviewers for their valuable comments and suggestions on the study.

\section{References}

1. Ratnayake, R.C. and Markeset, T. "Implementing company policies in plant level asset operations: measuring organisational alignment", European Journal of Industrial Engineering, 4(3), pp. 355-371 (2010).

2. Dahane, M., Rezg, N., and Clementz, C. "Subcontracting integration in a joint maintenance/production policy: study on profitability conditions", European Journal of Industrial Engineering, 5(4), pp. 412-423 (2011).

3. Nguyen, T.A.T. and Chou, S.Y. "Maintenance strategy selection for improving cost-effectiveness of offshore wind systems", Energy Conversion and Management, 157, pp. 86-95 (2018).

4. Lai, X., Chen, Z., and Bidanda, B. "Optimal decision of an economic production quantity model for imperfect manufacturing under hybrid maintenance policy with shortages and partial backlogging", International Journal of Production Research, 57(19), pp. 6061-6085 (2019). https://doi.org/10.1080/00207543.2018.1562249

5. Wang, Y.M. and Elhag, T.M. "Fuzzy TOPSIS method based on alpha level sets with an application to bridge 
risk assessment", Expert Systems with Applications, 31(2), pp. 309-319 (2006).

6. Panagiotidou, S. and Tagaras, G. "Evaluation of maintenance policies for equipment subject to quality shifts and failures", International Journal of Production Research, 46(20), pp. 5761-5779 (2008).

7. Al-Najjar, B. and Alsyouf, I. "Selecting the most efficient maintenance approach using fuzzy multiple criteria decision making", International Journal of Production Economics, 84(1), pp. 85-100 (2003).

8. Azadivar, F. and Shu, V. "Maintenance policy selection for JIT production systems", International Journal of Production Research, 37(16), pp. 3725-3738 (1999).

9. Alborzi, S., Aminian, A., Mojtahedi, S.M.H., et al. "An analysis of project risks using the non-parametric bootstrap technique". In 2008 IEEE International Conference on Industrial Engineering and Engineering Management, pp. 1295-1299 (2008, December).

10. Pascual, R. and Ortega, J.H. "Optimal replacement and overhaul decisions with imperfect maintenance and warranty contracts", Reliability Engineering \& System Safety, 91(2), pp. 241-248 (2006).

11. Bartholomew-Biggs, M., Zuo, M.J., and Li, X. "Modelling and optimizing sequential imperfect preventive maintenance", Reliability Engineering \& System Safety, 94(1), pp. 53-62 (2009).

12. Yuniarto, M.N. and Labib, A.W. "Fuzzy adaptive preventive maintenance in a manufacturing control system: a step towards self-maintenance", International Journal of Production Research, 44(1), pp. 159180 (2006).

13. Marmier, F., Varnier, C., and Zerhouni, N. "Proactive, dynamic and multi-criteria scheduling of maintenance activities", International Journal of Production Research, 47(8), pp. 2185-2201 (2009).

14. Davoudabadi, R., Mousavi, S.M., Mohagheghi, V., et al. "Resilient supplier selection through introducing a new interval-valued intuitionistic fuzzy evaluation and decision-making framework", Arabian Journal for Science and Engineering, 44(8), pp. 7351-7360 (2019).

15. Davoudabadi, R., Mousavi, S.M., S̆aparauskas, J., et al. "Solving construction project selection problem by a new uncertain weighting and ranking based on compromise solution with linear assignment approach", Journal of Civil Engineering and Management, 25(3), pp. 241-251 (2019).

16. Mousavi, S.M. "A new interval-valued hesitant fuzzy pairwise comparison-compromise solution methodology: an application to cross-docking location planning", Neural Computing and Applications, 31(9), pp. 5159-5173 (2019).

17. Gitinavard, H., Foroozesh, N., Mousavi, S.M., et al. "Soft computing based on a selection index method with risk preferences under uncertainty: applications to construction industry", International Journal of Computational Systems Engineering, 4(4), pp. 238-247 (2018).
18. Desai, S., Bidanda, B., and Lovell, M.R. "Material and process selection in product design using decisionmaking technique (AHP)", European Journal of Industrial Engineering, 6(3), pp. 322-346 (2012).

19. Foroozesh, N., Tavakkoli-Moghaddam, R., and Mousavi, S.M. "Sustainable-supplier selection for manufacturing services: a failure mode and effects analysis model based on interval-valued fuzzy group decisionmaking", International Journal of Advanced Manufacturing Technology, 95(9-12), pp. 3609-3629 (2018).

20. Labib, A.W., O'Connor, R.F., and Williams, G.B. "An effective maintenance system using the analytic hierarchy process", Integrated Manufacturing Systems, 9(2), pp. 87-98 (1998).

21. Bevilacqua, M. and Braglia, M. "The analytic hierarchy process applied to maintenance strategy selection", Reliability Engineering \& System Safety, 70(1), pp. 71-83 (2000).

22. Dey, P.K. "Decision support system for inspection and maintenance: a case study of oil pipelines", IEEE Transactions on Engineering Management, 51(1), pp. 47-56 (2004).

23. Shyjith, K., Ilangkumaran, M., and Kumanan, S. "Multi-criteria decision-making approach to evaluate optimum maintenance strategy in textile industry", Journal of Quality in Maintenance Engineering, 14(4), pp. 375-386 (2008).

24. Chatterjee, K. and Kar, S. "Unified Granular-numberbased AHP-VIKOR multi-criteria decision framework", Granular Computing, 2(3), pp. 199-221 (2017).

25. Chatterjee, K., Kar, M.B., and Kar, S. "Strategic decisions using Intuitionistic fuzzy VIKOR method for Information System (IS) outsourcing", In 2013 IEEE International Symposium on Computational and Business Intelligence, pp. 123-126 (August 2013).

26. Das, S. and Kar, S. "Group decision making in medical system: An intuitionistic fuzzy soft set approach", Applied Soft Computing, 24, pp. 196-211 (2014).

27. Das, S., Ghosh, P.K., and Kar, S. "Hypertension diagnosis: a comparative study using fuzzy expert system and neuro fuzzy system", In 2013 IEEE International Conference on Fuzzy Systems (FUZZ-IEEE), pp. 1-7 (July 2013).

28. Das, S., Kar, S., and Pal, T. "Robust decision making using intuitionistic fuzzy numbers", Granular Computing, 2(1), pp. 41-54 (2017).

29. Bertolini, M. and Bevilacqua, M. "A combined goal programming-AHP approach to maintenance selection problem", Reliability Engineering \& System Safety, 91(7), pp. 839-848 (2006).

30. Arunraj, N.S. and Maiti, J. "Risk-based maintenance policy selection using AHP and goal programming", Safety Science, 48(2), pp. 238-247 (2010).

31. Triantaphyllou, E., Kovalerchuk, B., Mann, L., et al. "Determining the most important criteria in maintenance decision making", Journal of Quality in Maintenance Engineering, 3(1), pp. 16-28 (1997). 
32. Luce, S. "Choice criteria in conditional preventive maintenance", Mechanical Systems and Signal Processing, 13(1), pp. 163-168 (1999).

33. Murthy, D.N.P. and Asgharizadeh, E. "Optimal decision making in a maintenance service operation", European Journal of Operational Research, 116(2), pp. 259-273 (1999).

34. Tahir, Z., Prabuwono, A.S., and Aboobaider, B.M. "Maintenance decision support system in small and medium industries: An approach to new optimization model", International Journal of Computer Science and Network Security, 8(11), pp. 155-162 (2008).

35. Sachdeva, A., Kumar, D., and Kumar, P. "A methodology to determine maintenance criticality using AHP", International Journal of Productivity and Quality Management, 3(4), pp. 396-412 (2008).

36. Kodali, R., Prasad Mishra, R., and Anand, G. "Justification of world-class maintenance systems using analytic hierarchy constant sum method", Journal of Quality in Maintenance Engineering, 15(1), pp. 47-77 (2009).

37. Meselhy, K.T., ElMaraghy, W.H., and ElMaraghy, H.A. "A periodicity metric for assessing maintenance strategies", CIRP Journal of Manufacturing Science and Technology, 3(2), pp. 135-141 (2010).

38. Labib, A.W. "A decision analysis model for maintenance policy selection using a CMMS", Journal of Quality in Maintenance Engineering, 10(3), pp. 191202 (2004).

39. Ghosh, D. and Roy, S. "A decision-making framework for process plant maintenance", European Journal of Industrial Engineering, 4(1), pp. 78-98 (2009).

40. Pariazar, M., Shahrabi, J., Zaeri, M.S., et al. "A combined approach for maintenance strategy selection", Journal of Applied Sciences, 8(23), pp. 4321-4329 (2008).

41. Chan, F.T. and Prakash, A. "Maintenance policy selection in manufacturing firms using the fuzzy MCDM approach", International Journal of Production Research, 50(23), pp. 7044-7056 (2012).

42. Jafari, A., Jafarian, M., Zareei, A., et al. "Using fuzzy Delphi method in maintenance strategy selection problem", Journal of Uncertain Systems, 2(4), pp. 289-298 (2008).

43. Li, C., Xu, M., and Guo, S. "ELECTRE III based on ranking fuzzy numbers for deterministic and fuzzy maintenance strategy decision problems", In IEEE International Conference on Automation and Logistics, pp. 309-312 (August 2007).

44. Pourjavad, E., Shirouyehzad, H., and Shahin, A. "Selecting maintenance strategy in mining industry by analytic network process and TOPSIS", International Journal of Industrial and Systems Engineering, 15(2), pp. 171-192 (2013).

45. Ding, S.H. and Kamaruddin, S. "Maintenance policy optimization-literature review and directions", International Journal of Advanced Manufacturing Technology, 76(5-8), pp. 1263-1283 (2015).
46. Ding, S.H., Kamaruddin, S., and Azid, I.A. "Development of a model for optimal maintenance policy selection", European Journal of Industrial Engineering, 8(1), pp. 50-68 (2014).

47. Nazeri, A. and Naderikia, R. "A new fuzzy approach to identify the critical risk factors in maintenance management", International Journal of Advanced Manufacturing Technology, 92(9-12), pp. 3749-3783 (2017).

48. Mechefske, C.K. and Wang, Z. "Using fuzzy linguistics to select optimum maintenance and condition monitoring strategies", Mechanical Systems and Signal Processing, 17(2), pp. 305-316 (2003).

49. Sugumaran, C., Muthu, S., Devadasan, S.R., et al. "From TPM to analytic maintenance quality function deployment: a literature journey via QFD and AHP", International Journal of Indian Culture and Business Management, 4(4), pp. 390-418 (2011).

50. Maletič, D., Maletič, M., Lovrenčić, V., et al. "An application of analytic hierarchy process (AHP) and sensitivity analysis for maintenance policy selection", Organizacija, 47(3), pp. 177-188 (2014).

51. Rahimi, M., Sadinejad, S., and Khalili-Damghani, K. "Selecting the most appropriate maintenance strategies using fuzzy analytic network process: a case study of Saipa vehicle industry", Decision Science Letters, 3(2), pp. 237-242 (2014).

52. Azadeh, A. and Abdolhossein Zadeh, S. "An integrated fuzzy analytic hierarchy process and fuzzy multiplecriteria decision-making simulation approach for maintenance policy selection", Simulation, 92(1), pp. 3-18 (2016).

53. Hemmati, N., Rahiminezhad Galankashi, M., Imani, D.M., et al. "An integrated fuzzy-AHP and TOPSIS approach for maintenance policy selection", International Journal of Quality \& Reliability Management, $\quad \mathbf{3 7}(9 / 10)$, pp. 1275-1299 (2020). https://doi.org/10.1108/IJQRM-10-2018-0283

54. Khalaj, M., Tavakkoli-Moghaddam, R., Khalaj, F., et al. "New definition of the cross entropy based on the Dempster-Shafer theory and its application in a decision-making process", Communications in Statistics-Theory and Methods, 49(4), pp. 909-923 (2020).

55. Mokhtarian, M.N., Sadi-nezhad, S., and Makui, A. "A new flexible and reliable interval valued fuzzy VIKOR method based on uncertainty risk reduction in decision making process: An application for determining a suitable location for digging some pits for municipal wet waste landfill", Computers \& Industrial Engineering, 78, pp. 213-233 (2014).

56. Ashtiani, B., Haghighirad, F., Makui, A., et al. "Extension of fuzzy TOPSIS method based on intervalvalued fuzzy sets", Applied Soft Computing, 9(2), pp. 457-461 (2009).

57. Zhang, W.G., Wang, Y.L., Chen, Z.P., et al. "Possibilistic mean-variance models and efficient frontiers for portfolio selection problem", Information Sciences, 177(13), pp. 2787-2801 (2007). 
58. Ye, F. and Lin, Q. "Partner selection in a virtual enterprise: A group multiattribute decision model with weighted possibilistic mean values", Mathematical Problems in Engineering, 2013 (2013). https://doi.org/10.1155/2013/519629

59. Deng, X. and Li, R. "Gradually tolerant constraint method for fuzzy portfolio based on possibility theory", Information Sciences, 259, pp. 16-24 (2014).

60. Foroozesh, N., Tavakkoli-Moghaddam, R., Mousavi, S.M., et al. "Dispatching rule evaluation in flexible manufacturing systems by a new fuzzy decision model with possibilistic-statistical uncertainties", Arabian Journal for Science and Engineering, 42(7), pp. 29472960 (2017).

61. Dubois, D., Lang, J., and Prade, H. "Theorem proving under uncertainty: a possibility theory-based approach", In Proceedings of the 10th International Joint Conference on Artificial Intelligence, 2, pp. 984986 (August 1987).

62. Goetschel Jr, R. and Voxman, W. "Elementary fuzzy calculus", Fuzzy Sets and Systems, 18(1), pp. 31-43 (1986).

63. Al-Najjar, B. "Condition-based maintenance: Selection and improvement of a cost-effective vibrationbased maintenance policy for rolling element Bearings", Lund University (1997).

64. Kelly, A., Maintenance Strategy. Elsevier (1997).

65. Chen, D. and Trivedi, K.S. "Closed-form analytical results for condition-based maintenance". Reliability Engineering \& System Safety, 76(1), pp. 43-51(2002).

66. Samrout, M., Chĉtelet, E., Kouta, R., et al. "Optimization of maintenance policy using the proportional hazard model", Reliability Engineering \& System Safety, 94(1), pp. 44-52 (2009).

67. Selim, M. and Gurel, A.S. "Machining conditionsbased preventive maintenance", International Journal of Production Research, 45(8), pp. 1725-1743 (2007).

68. Bamber, C.J., Sharp, J.M., and Hides, M.T. "Factors affecting successful implementation of total productive maintenance: a UK manufacturing case study perspective", Journal of Quality in Maintenance Engineering, 5(3), pp. 162-181(1999).

69. Grall, A., Dieulle, L., Bérenguer, C., et al. "Continuous-time predictive-maintenance scheduling for a deteriorating system", Reliability, IEEE Transactions on, 51(2), pp. 141-150 (2002).

70. Willmott, P., Total Productive Maintenance: The Western Way, Butterworth-Heinemann (1997).

71. Sherwin, D. "A review of overall models for maintenance management", Journal of Quality in Maintenance Engineering, 6(3), pp. 138-164 (2000).
72. Crocker, J. and Kumar, U.D. "Age-related maintenance versus reliability centred maintenance: a case study on aero-engines", Reliability Engineering \& System Safety, 67(2), pp. 113-118 (2000).

73. Azadivar, F. "Simulation optimization methodologies", In Proceedings of the 31 st Conference on Winter Simulation: Simulation-a Bridge to the Future, 7, pp. 93-100, ACM (1999, December).

74. Goldsman, D., Nelson, B.L., Opicka, T., et al. "A ranking and selection project: experiences from a university-industry collaboration", In Proceedings of the 31st Conference on Winter Simulation: Simulation-a Bridge to the Future, 1, pp. 83-92, ACM (December 1999).

75. Au-Yong, C.P., Ali, A.S., and AhmAd, F. "Prediction cost maintenance model of office building based on condition-based maintenance", Eksploatacja $i$ Niezawodnosc-Maintenance and Reliability, 16(2), pp. 319-324 (2014).

76. Chen, T.Y. "Comparative analysis of SAW and TOPSIS based on interval-valued fuzzy sets: Discussions on score functions and weight constraints", Expert Systems with Applications, 39(2), pp. 1848-1861 (2012).

\section{Biographies}

Nazanin Foroozesh now is a PhD student at the Department of Industrial Engineering and Management Systems, Amirkabir University of Technology, Tehran, Iran. She received her MSc from School of Industrial Engineering, University of Tehran, Iran in 2018. Her main research interests include fuzzy sets theory, multicriteria decision-making under uncertainty, resilient and sustainable supply chain, and applied operations research. She has published several papers in reputable journals and international conference proceedings.

Seyed Meysam Mousavi is an Associate Professor at the Department of Industrial Engineering, Faculty of Engineering, Shahed University in Tehran, Iran. He received a $\mathrm{PhD}$ degree from the School of Industrial Engineering at University of Tehran, Iran and is currently a member of Iran's National Elite Foundation. $\mathrm{He}$ is the Head of Industrial Engineering Department at Shahed University and a member of the Iranian Operational Research Association. His main research interests include cross-docking systems planning, logistics planning and scheduling, quantitative methods in project management, engineering optimization under uncertainty, and multi-criteria decision-making under uncertainty, and applied soft computing. He has published many papers and book chapters in reputable journals and international conference proceedings.

Mohammad Mojtahedi is a Senior Lecturer at the Faculty of Built Environment at the University of New 
South Wales, Australia. He completed his $\mathrm{PhD}$ in the School of Civil Engineering at The University of Sydney in 2014. He has applied his knowledge in disaster risk management and resiliency of buildings and infrastructure over the past years. He is a Pioneer in Australia in combining city planning, operations research, and engineering to enhance the resilience of urban and rural buildings and infrastructure through disaster risk management. He has been invited as a keynote speaker in more than 20 international conferences and symposiums. He has received several national and international travel grants designed to provide outstanding early career researchers with the opportunities to network with reputable researchers in the field of disaster risk management and resilient built environment across the world.

Hossein Gitinavard is currently a PhD student at the Department of Industrial Engineering and Management Systems, Amirkabir University of Technology, Tehran, Iran. He received his MSc and BSc degrees from the School of Industrial Engineering, Iran University of Science and Technology, and School of Industrial Engineering, University of Tehran, Iran in 2015 and 2013, respectively. His main research interests include fuzzy sets theory, supply chain management, multicriteria decision-making under uncertainty, and applied operations research. He has published several papers in reputable journals and international conference proceedings. 